\title{
7 Conclusion
}

\begin{abstract}
This chapter concludes the book. It outlines the key findings and provides a summary of the main arguments. The chapter ends by examining areas where future research could build on the approaches and findings to further improve our understanding of microcredit and rural development in China and elsewhere.
\end{abstract}

Keywords: China, rural development, microcredit, financial inclusion, marginalisation, relational approach

The very language we use to describe the self-made ideal has these fault lines embedded within it: To 'pull yourself up by your bootstraps' is to succeed by dint of your own efforts. But that's a modern corruption of the phrase's original meaning. It used to describe a quixotic attempt to achieve an impossibility, not a feat of self-reliance.

-John Swansburg ${ }^{1}$

This book represents the distillation, synthesis, and analysis of a large qualitative data set - consisting of systematic observation, interviews, conversations, photos/videos, and a variety of different types of documentary material. This data was collected over more than half a year of in-depth empirical fieldwork, primarily in three townships in rural Jiangxi Province, but also at the county, prefecture, and provincial levels. Through a broad, exploratory, and open research orientation - paired with a grounded methodological design - this research project has sought to texturise and deepen our understanding of how government microcredit is formulated, implemented, and perceived at the local level. In this way, this book departs from conventional mainstream research on microcredit and rural finance

1 See (Swansburg, 2014).

Loubere, Nicholas, Development on Loan: Microcredit and Marginalisation in Rural China. Amsterdam, Amsterdam University Press 2019 DOI: 10.5117/9789463722513_CHO7 
in China, which is dominated by the disciplines of finance and economics, quantitative and positivistic approaches, normative conceptions of the benefits of financial inclusion, and a focus on systems and/or institutions rather than local actors themselves. This concluding chapter summarises and highlights the main findings, and outlines the key ways in which future research can build on the work in this book - and address its limitations - in order to further improve our understanding of how microcredit programmes in particular, and rural development interventions in general, are implemented at the local level; and the ways in which they facilitate, transform, and/or (re)produce processes of (under)development and (de)marginalisation in the context of rural China and elsewhere.

\subsection{In Summary}

The book began in Chapter 1 by outlining the trajectory of socioeconomic development in rural China since the initiation of economic reforms in the 1970 and detailing the parallel evolution of the global microfinance movement. This was followed by an analysis of the ideological similarities between the two movements - and the wholesale the adoption of microcredit as a means of promoting rural development in the country. The chapter then went on to outline the objectives of the book and provide an overview of the methodological approach and field sites. Chapter 2 opened with an historical overview of the transformation of the rural financial system in China since the establishment of the PRC in 1949 in order to contextualise microcredit's place in the dynamic rural financial landscape. This was followed by a comprehensive review of the literature on rural finance and development in the country, ending with a detailed analysis of the key strengths and weaknesses in our current understanding of the nexus between rural finance, local development, and livelihoods.

Chapter 3 outlined the policies and practices of the three microcredit programmes examined in this book - the PAMP, RCCMP, and EMP - based on the empirical fieldwork conducted in the three townships. The chapter began by examining microcredit policy formulation at the national and provincial levels based on analysis of primary policy documents and interviews with government officials. It then identified key areas where the policies have been left relatively open to interpretation, allowing for flexible experimentation by local implementers. The chapter went on to detail the realities of the local implementation of each of the programmes in the three townships - revealing high levels of heterogeneity. Chapter 
4 analysed the key reasons for this heterogeneous implementation at the local level. It began by examining the ways in which differentiated financial landscapes and segmented financial markets influenced local interpretations and understandings of microcredit as a resource, before going on to look at how exogenous and endogenous pressures and incentives were internalised in varied ways by local implementers. The final sections of the chapter illustrated how implementation outcomes were complex and emergent -pointing to heterogeneous implementation as being relational in nature, rather than the outcome of top-down linearity.

Chapter 5 and Chapter 6 analysed the ways in which the heterogeneous and emergent implementation resulted in the microcredit programmes facilitating certain processes of development and de-marginalisation, while simultaneously producing and feeding into undercurrents of marginalisation, albeit in different ways across the three localities. Specifically, Chapter 5 began by showing how the programmes have enabled flows of capital, knowledge, and technology from more developed, non-marginal regions and actors to the three townships. The chapter then illustrated the ways in which the programmes have played a role in the formation and strengthening of new socioeconomic and socio-political linkages, while also contributing to the creation of modern modes of employment, cooperation, and inclusion at the local level. This has facilitated the de-marginalisation of some actors and the improvement of certain livelihoods. Chapter 6 responded by detailing the microcredit programmes' simultaneous production of marginalisation. In particular, the chapter pointed to the different ways that the programmes facilitated the diversion and extraction of resources from marginal to non-marginal actors/areas, and the fact that the programmes reflected and reproduced various forms of socioeconomic exclusion at different levels, ultimately exacerbating already precarious livelihoods by transferring risk to marginal actors and facilitating their exploitation in different ways depending on the programme and location.

\subsection{Key Findings}

This book expands our knowledge of how microcredit programmes are implemented, the types of 'impact' they have, and how we should perceive microcredit's role in socioeconomic development and the (re)production of rural livelihoods in China and elsewhere. With regard to implementation, this book illustrates that while microcredit has been increasingly identified as a means of facilitating rural development and de-marginalisation by 
the central, provincial, and local governments; the actual implementation and perceptions of the microcredit programmes has been characterised by extreme variation across the three townships and at different points in time. To a certain extent, this heterogeneity can be traced back to the policy formulation of the three programmes at the central and provincial levels. While all three programmes explicitly sought to de-marginalise rural actors, the types of de-marginalisation envisioned varied, and often reflected the shifting development ideologies and priorities that were dominant at the time of their conceptualisation. The PAMP was initiated in the 1980 s when rural poverty was seen as the most visible and pressing manifestation of rural marginality. The RCCMP was conceptualised over a decade later at the turn of the century, and reflected the dominant perception that financial inclusion was the answer to de-marginalisation in rural China. The EMP, on the other hand, is the most recent policy addition to China's ongoing financially-oriented rural development efforts, and depicts rural de-marginalisation as being instigated by local entrepreneurship.

All of these visions of microcredit as a facilitator of rural de-marginalisation fit squarely within the linear progression development paradigm. However, they are also flexible, allowing for shifting developmental priorities at different levels. For instance, the PAMP has been reformulated and coopted by a number of different overarching development frameworks over the course of its existence. At the same time, the policy wording for all the programmes is vague, allowing for local experimentation. This means that both the central formulation and local implementation of the microcredit programmes have been marked by dynamism and influenced by diverse perspectives at different levels, resulting in high levels of variation in implementation outcomes across time and space. Indeed, with all three programmes across all three localities the most recognisable pattern or 'norm was the uniqueness of diversity' (Chambers, 2014, p. 53). Like other research, this book began by outlining some of the key 'variables' contributing to this heterogeneous implementation. This included contextual factors - such as differentiated financial landscapes and differently segmented financial markets. It also included exogenous/endogenous pressures and incentives - such as quotas, career considerations, distributions of power, and time/resource constraints. However, unlike most research on external development interventions in China or elsewhere, this book determines that these variables are themselves dynamic, heterogeneous, and context/ time specific. This means that the actual implementation outcomes were not the sum of variables and constants, but the result of a confluence of diverse and unpredictable factors, making it impossible to accurately predict 
or generalise key determinants influencing implementation in each case. More significantly, the book concluded that these infinite variables were not equally weighted, and that their importance in shaping implementation was mediated by relational considerations. Simply put, the implementation of the programmes was influenced by a wide range of factors, which were perceived differently by actors at different levels and with different amounts of involvement and power in the programmes. These actors then entered into negotiation with each other, ultimately producing the varied implementation outcomes. These outcomes were not static, but rather dynamic and shifting based on continuous and ongoing negotiations.

Therefore, the implementation of the microcredit programmes can best be characterised as complex, emergent, and inherently relational in nature. This contrasts with dominant mainstream conceptualisations of development interventions as linear - travelling from central formulation to local implementation with clear goals and intended outcomes based on the 'medical-esque' diagnosis of a problem that requires 'treatment' (Long, 2001). This dominant understanding of linear development perceives heterogeneous implementation as the result of 'irregularities' or 'distortions' that can and should - be eliminated through strict adherence to 'best practice'. The heterogeneous implementation marked by high levels of complexity outlined in this book, however, illustrates that development interventions in general, and microcredit programmes in particular, should actually be understood as 'self-organising systems on the edge of chaos' (Chambers, 2008, p. 174). This is because any external intervention is ultimately locally internalised and reconstituted, and thus transformed into a local 'socially constructed and negotiated process, not simply the execution of an already-specified plan of action with expected outcomes' (Long, 1999, p. 4). In other words, attempting to determine sets of 'constants', 'variables', and 'determinants' represents the application of unsuitable natural science methods to dynamic and complex social situations, thereby creating oversimplification and misleading analyses. Rather, development interventions such as microcredit need to be understood as more than the sum of their parts - emergent from relational processes that are co-produced at the interfaces of interaction between diverse actors.

This book has also illustrated how the complex, emergent, and heterogeneous implementation of the microcredit programmes in the three townships has necessarily resulted in differentiated and paradoxical 'impact'. This means that the programmes played a variety of very different roles in local development strategies and the livelihoods of diverse local actors. Rather than inducing some uniform vision of development and de-marginalisation through a top-down linear causal chain of events, the programmes instead tended to 
reflect different perceptions of what development and de-marginalisation actually entails. This, again, emerged from the negotiations between different actors based on their interpretations of the wider political economy of development. In this way, the roles of the programmes - while still situated within the linear progression development paradigm - were largely framed by local contexts and/or the individuals and groups who wielded the most power in negotiations over implementation. For instance, in the AT the EMP and RCCMP were utilised to finance different types of investment in agriculture, in the MWT microcredit was diverted to large industry, and in the DET the programmes largely funded microenterprises and SMEs. In other words, in the same way as the processes of implementation, microcredit utilisation and the resultant impacts were complex, emergent, and basically unpredictable, as the programmes became facilitators of (de)marginalisation for distinctly different sectors, groups, and individuals in each of the three localities.

These complex impacts fed into processes of uneven development, resulting in paradoxical outcomes. Indeed, rather than eliminating development dichotomies, microcredit actively reproduced and strengthened marginal relationships and unequal structures of power at different levels. Therefore, instead of playing beneficial roles in development and livelihoods, the programmes produced contradictory 'impacts' by enabling de-marginalisation for some, while simultaneously feeding into undercurrents of marginalisation for others. While the programmes can be credited with facilitating flows of capital, knowledge, and technology from central to local areas and actors, the formation of new socioeconomic and socio-political linkages, and the promotion of new forms of employment, cooperation, and inclusion; they also allowed for the diversion and extraction of rural resources, produced various types of socioeconomic exclusion, and played a role in the exacerbation of livelihood precarity by enabling the exploitation of marginal actors. In this way, microcredit largely reflected China's paradoxical development landscape by reproducing both dynamic and durable inequalities at different levels, albeit in diverse ways across the three localities. Ultimately, therefore, both implementation and impact were complex, emergent, and inherently relational in nature. This resulted in multidimensional, dynamic, and unpredictable outcomes, which were perceived as beneficial by some and detrimental by others, rendering attempts at aggregate generalisation about impact meaningless.

The findings outlined above contradict the dominant understanding of development as 'emanating primarily from external centres of power via interventions by the state or international bodies, and following some broadly determined developmental path, signposted by "stages of development", and instead expose the linear progression development paradigm as being 
'tainted by determinist, linear and externalist views of social change' (Long, 2001, pp. 10-11). Moreover, and more importantly, these findings point to the fact that the very marginality that microcredit and other development interventions seek to eliminate is itself the product of unequal relationships at different levels, which are mutually constituted and co-produced at the interfaces of interaction between different actors and areas. These patterns of inequality, marginality, and the ensuing exploitation and impoverishment are 'not just part of nature' (Kirk, Brewer, \& Hickel, 2015, p. N/A) - i.e. stages that can be evolved out of - but are, instead, socially constructed within regimes characterised by differentiated structures of power and subordination.

The relational and dichotomously mutually-constituted nature of the concepts of development and underdevelopment, centrality and marginality, prosperity and impoverishment, etc., is particularly evident in the neoliberal version of the linear progression development paradigm - embodied by microcredit and adopted by China since the reform and opening. This is because neoliberal linear progressive development explicitly necessitates the production of 'winners' and 'losers' in the quest to instigate developmental progress. It is an unavoidable zero-sum game due to 'the difficult fact that the processes that allow some to escape from poverty traps are the same that allow the exploitation of others' (Mosse, 2010, p. 1172). In the words of Henry Bernstein: 'there are no win-win solutions within capitalism' (Bernstein, 2010, p. 98). From this perspective, neoliberal linear progressive development is itself responsible for the continued production of the 'third world' that it purports to be in the process of eliminating (Escobar, 1995).

Microcredit is 'the neoliberal development strategy par excellence' (Hickel, 2015, p. N/A), as it depicts underdevelopment and marginalisation as simply being the result of exclusion from the market system. Reasons for this exclusion are framed as local issues, such as the spatial marginality of a given locality due to its distance from developed centres, and/or temporal marginality resulting from the 'backward' mentalities of the local inhabitants. Discussions of power disparities and exploitation are also limited to the local level, where 'traditional' perceptions of gender and class, or established local power structures, are blamed for exclusion from the all-empowering market. Expanding the provision of credit, therefore, is depicted as essentially de-marginalising in and of itself, as it brings those on the margins into the formal financial system, thereby integrating them into the wider capitalist economy. This inclusion is also seen to have the potential to transform the 'backward' and 'traditional' attitudes and habits of the marginal populace into modern ones of higher 'quality' (suzhi), thus smoothing over inequalities in opportunity created by local power disparities. 
In other words, microcredit does not perceive marginality and poverty 'as a consequence of a particular way in which society is organised through relations of power and domination [...] [but] as the consequences of unfulfilled market potentials' (Weber, 2006, p. 44). By individualising and localising the causes of marginality, microcredit effectively ignores the wider structures of power and durable inequalities that are ultimately responsible for the production of marginalisation. This individualisation of developmental responsibility obscures microcredit's role as a financing mechanism - and creator of debt - for a system that requires the creation of 'winners' at the expense of 'losers'. In reality, this means that microcredit providers either have to exclude some 'unsuitable' borrowers at the local level due to their perceived inability to repay, or lend to everyone and accept the fact that some projects will fail, resulting in the exacerbation of the precarity of already marginal livelihoods. In this way, microcredit ascribes unrealistic de-marginalising abilities to the 'free market', ignoring the fact that economic liberalisation often benefits the already powerful. To put this another way and return to the quotation at the beginning of Chapter 6, 'microfinance does not simply smooth over contemporary processes of agrarian change. Rather, it tends to reflect and reproduce their central contradictions and power dynamics' (Taylor, 2012, p. 6og).

Ultimately, therefore, while microcredit undoubtedly has the ability to produce certain forms of de-marginalisation for some areas and actors, it is also the reflection of sets of interlocking and mutually constituted 'development dichotomies', and thereby necessitates the (re)production of durable inequalities and marginal relationships at different levels. This means that microcredit does not have the ability to eliminate marginality or underdevelopment, regardless of whether or not 'best practices' are followed, but instead can only diminish some marginal relationships while strengthening others or creating new ones. This fundamental inability of microcredit to address the underlying reasons for the production of marginality was perhaps most concisely expressed by the head of one poor household in the AT in response to a question about how microcredit could better serve him and other marginal actors in the community:

I don't have any recommendations. We cannot afford to buy a house, we have just enough to eat and no money saved. Even if the village built a credit union it wouldn't help. Without a basic amount of money, there is no help for normal villagers. ${ }^{2}$ 
Microcredit does not just fail in its goal, however. It also systematically shifts the responsibility for development and de-marginalisation to the poor and marginal themselves, thus inherently exacerbating their precarity (Loubere, 2017d). This mirrors the increasingly commercialised development orientation in rural China over the past decades, within which individuals have been made responsible for their own development, with 'self-sufficiency' becoming a primary goal. This has rendered 'humanistic modernisation' (rende xiandaihua) and the improvement of 'quality' (suzhi) individual imperatives and even patriotic duties (Barabantseva, 2009; Murphy, 2004), thus putting the onus on marginal actors to change their own socioeconomic conditions by 'pulling themselves up by their own bootstraps'. In this way, marginality is effectively de-historicised and de-contextualised through the obfuscation of the unequal relationships of power that gave rise to it in the first place - thereby rendering marginalisation a technical, rather than relational, issue (Kirk et al., 2015; Li, 2007). This not only lets those responsible for the marginalisation of others off the hook, but it also recasts them as the providers of development resources and knowledge. Those at the margins become indebted to the prosperous centres, which are given credit for lending out the 'gift of development' (Yeh, 2013). In return for this development on loan, marginalised people are expected to display gratitude, obedience, and further integrate themselves into the exploitative socioeconomic system. This mirrors the ways in which microcredit reinforces social codes of shame and honour in Bangladesh (Karim, 2011), promotes marketised conceptions of freedom in India (Guérin \& Kumar, 2017) and facilitates multiple forms of dispossession in Egypt (Elyachar, 2005).

Implicit in these multi-tiered debt relations between the margins and the centre is an imperative to convert and transform - a form of economic proselytism that reflects wider civilisational and modernising imperatives at work in contemporary China (Barmé \& Goldkorn, 2013). Marginal groups and areas must abandon their 'backward' modes of socioeconomic organisation and adopt the behaviours and mindsets necessary to participate in the modern financial system. At one level, this means that marginal groups must be taught things, such as 'financial literacy' in order to improve their 'financial decision making'. In the words of the World Bank: 'It is possible to enhance financial capability - financial knowledge, skills, attitudes, and behaviors - through well-designed, targeted interventions. Financial education has a measurable impact if it reaches people during teachable moments [...]' (World Bank, 2014, pp. 3-4). However, this transformational imperative goes beyond simply learning new skills and behaviours, and instead implies the need to instil an entirely new 'financial consciousness' 
in marginal subjects. The promise of microcredit and financial inclusion is not only that those at the margins will gain access to previously inaccessible resources, but that they will also become enlightened and able to reach their full human potential. They are transformed through their integration into the formal financial system from 'backward' people who were unable to make sound economic decisions, to highly-functioning rational actors operating based on superior market logics. In the words of Muhammad Yunus:

The first and foremost task of development is to turn on the engine of creativity inside each person [...] This is why Grameen Bank offers the poor not handouts or grants but credit - loans they must repay, with interest, through their own productive work [...] It also helps the poor demonstrate to themselves that they can change their world for the better - and it gives them the tools to do just that, for themselves (Yunus \& Weber, 2007, p. 56).

Conceptualising microcredit as a form of conversion therapy reveals that financial inclusion is not actually inclusive, as it systematically subordinates certain forms of socioeconomic knowledge and organisation, and requires adherence to a uniform mode of operation. The creative energies referred to by Yunus can only be channelled into a specific type of economic activity circumscribed and mediated by the market. Traditional forms of financial knowledge and activity - often characterised by informality and nonindividualised logics - are framed as being incompatible with the modern operations of the formal financial system, and must be discarded. From this perspective, financial inclusion represents a potentially destructive act of cultural transfiguration. This is most obviously illustrated by the Hui migrant family in the MWT discussed in Chapter 6. In order to successfully integrate into the formal financial system they would have to forsake their own mode of financial organisation, which was rooted in uncountable and informal communal relations. They would also have to disregard certain aspects of their religious faith dictating that they cannot lend or borrow at interest. While not all local informal institutions are dismantled by the expansion of the formal financial system, few are left completely untouched by financialised logics that accompany economic integration. This is significant because it is often informal local institutions and arrangements that provide the most effective means of forming solidarity and contesting unequal power relations through collective action. Microcredit suppresses the informal collective in favour of the mythical individual entrepreneur, 
and in this way feeds into wider developmental processes that reduce the capacity of those on the margins to challenge the long-running historical socioeconomic relations that gave rise to their marginality in the first place.

In sum, microcredit is a key component in a development ideology that creates the very marginalisation and underdevelopment that it purportedly seeks to eliminate. Therefore, while we cannot generalise about how microcredit programmes will be implemented at the local level or predict the precise patterns of impact that they will produce in different contexts, this book has clearly illustrated that microcredit seeks to address the symptoms of systemic marginalisation, while not only ignoring the fundamental causes that it is implicated in creating, but also shifting responsibility for them to marginal actors and demanding their transformation. Simply put, microcredit does not produce any 'win-win' or net reduction in marginality, but is instead embedded within, and contributes to, shifting patterns of marginalisation and underdevelopment at the local level.

\subsection{Directions for Future Research}

This book represents an initial attempt to explore government microcredit in China in a grounded holistic way, and therefore has its own limitations and areas that require further scrutiny. Future research on microcredit and rural development - both in China and globally - can build on the findings presented here and address some of the study's limitations in a number of important ways. Firstly, future research should be aware from the outset of the need to be more reflexive and critical of the normative categories underpinning the concepts of development, modernisation, and de-marginalisation, which are primarily defined by (neo)classical economic theories and an "ethnocentric "Western" model of social behaviour based upon the individualism of "utilitarian man" that rides roughshod over the specificities of culture and context' (Long, 2001, p. 14). In particular, future research should move away from the misleading characterisation of underdevelopment, marginalisation, and poverty as necessary stages of development that can simply be progressed out of by identifying models to emulate or 'best practices' to follow. As stated above, this linear and universalist understanding of progressive development de-historicises and de-contextualises the 'afflictions' of underdevelopment and marginalisation, essentially detaching them from the very conditions that result in their production. Therefore, future research should take care to conceptualise underdevelopment, marginality, and poverty as relational issues that are 
produced at the interfaces of interaction between actors at different levels, and across time and space (Escobar, 1995; Mosse, 2010).

This shift towards an actor-oriented relational approach to understanding development and marginality will allow for a more nuanced, historicised, contextualised, and realistic depiction of the processes involved in implementing development interventions in general, and microcredit programmes in particular, as well as their complex and multidimensional outcomes and impacts. Future inquiry could enrich this approach by drawing on research in a variety of fields and disciplines. For instance, research on decision making in behavioural psychology could complement and improve our understanding of implementers as 'street-level bureaucrats' by shining a light on how individual perceptions and group dynamics shape implementation at the local level (Kahneman, 2012; Kahneman \& Tversky, 1979; Lipsky, 1980; Tversky \& Kahneman, 1992). At the same time, by drawing more heavily on the classic literature on 'unintended consequences' in the field of global development (Hirschman, 1967), alongside a deeper engagement with the emerging body of research on 'complexity theory' in both the natural and social sciences - focusing on chaos, self-organising systems, non-linearity, and emergence - future research could potentially create a framework for understanding heterogeneity, both with regard to implementation and impact (Chambers \& Loubere, 2017; Escobar, 2004; Hobbes, 2014; Ramalingam, 2013).

Additionally, the issue of multidimensional power needs to be placed at the centre of inquiry. Too often the current body of research frames power as two-dimensional, depicting local structures of power as adhering to a uniform - thus predictable - hierarchy, and framing the local powerful 'elite' as the biggest threat to successful microcredit implementation due to their homo economicus-induced lust for subsidised credit. This ignores the ways in which unequal power relationships manifest themselves in diverse ways at different levels, resulting in dynamic patterns of marginalisation and differentiated developmental landscapes within which the programmes are formulated and implemented. Therefore, it is crucial that future research draws on the established body of literature on multidimensional power, which explores diverse forms of durable inequality and exploitation (Foucault, 1982; Hathaway, 2016; Lukes, 2005; Mosse, 2010; Tilly, 1998), in order to better understand the unequal marginal relationships that underpin microcredit implementation and outcomes. This is of particular importance as a means of critiquing the notion of 'empowerment' as being one of the results of microcredit, which ignores the fact that the relationship between creditor and debtor is inherently unequal and implicitly premised on the 
threat of violence. In the words of David Graeber: 'there's no better way to justify relations founded on violence, to make such relations seem moral, than by reframing them in the language of debt [...] because it immediately makes it seem that it's the victim who's doing something wrong' (Graeber, 2011).

In order to shift from a linear to a relational mode of inquiry, future research could also build on and improve the grounded ethnographic methodological approach and specific methods employed and pioneered in this research project. In particular, projects exploring microcredit or other development interventions could utilise, adapt, and improve the Systematic and Reflexive Interviewing and Reporting (SRIR) method, in order to better map complex marginal relationships at the local level (Loubere, 2017c). In particular, the application of participatory methodological approaches could provide a fruitful basis for adapting the methods employed in the research for this book. For instance, 'systematic interview reports' could be co-produced in participatory groups and 'reflexive dialogues' could be expanded to include research subjects as well as researchers. Moreover, other participatory methods could be utilised, such as participatory wealth ranking, transect walks, participatory mapping, participatory video/photography, etc. (Chambers \& Loubere, 2017; Shah, 2016), which would serve to provide a more nuanced depiction of how local people perceive the webs of marginal relationships that shape their development landscapes. At the same time, the detailed ethnographic portraits produced by the methods described above could be strengthened and corroborated by quantitative methods, such as participatory statistics and network analysis (Holland, 2013; Scott, 2012). Traditional statistical methods could also be utilised to explore marginal relationships at the meso and macro levels by mapping out flows of capital and other resources between rural and urban areas/ actors, thereby providing a clearer picture of the processes underpinning the wider political economy of development. While this still would not allow for aggregate generalisation, it would provide the means to theorise at multiple levels and extrapolate more precise understandings of the role that microcredit plays in different development landscapes. Ideally, therefore, future research projects would involve larger research teams operating in a variety of localities, at different levels, and employing mixed-methods approaches. These teams could systematically adapt and improve some of the basic methodologies utilised in this book in order to map out marginal relationships across China and within localities, thereby more completely outlining where processes of marginalisation emerge from, how they manifest themselves across time and space, and how different development interventions engage with marginality at different levels. 
Rural China's financial and development landscapes are in a state of rapid and sustained flux. This points to the need for continued research that engages with these processes in-depth, but also quickly produces outputs that keep up with the dynamism of the environment. For this reason, research projects should look back to some of the key principles of RRA (Chambers, 1994, 2008; Chambers \& Loubere, 2017), and also utilise quick and open access dissemination mediums. This issue is most obviously highlighted by the fact that recent major shifts in the systemic and ideological structuring of the rural financial landscape - such as the introduction of the EMP, the legalisation of new commercialised and cooperative financial service providers (MLCs, VTBs, and RMCCs), the increased prevalence of the 'financial systems approach' as the operational principle of traditional financial service providers, the introduction (or return) of state-owned commercial banks to the countryside, and the advent of digital finance - have not yet been the subject of much in-depth research in English. Considering the importance that financial systems and institutions play in promoting different versions of development - and the potential they have to cause serious crisis, even destroying local and national economies, and exacerbating inequality and marginalisation - there can be no doubt that China's rapidly shifting rural financial terrain needs to be continuously and vigilantly monitored. At the same time, our understanding of what financial systems and services mean for local development and livelihoods needs to be broadened, and the perspectives and voices of all the actors involved - especially the most marginal - need to be recorded, represented, and analysed in a more balanced way going forward.

\section{Bibliography}

Barabantseva, V. E. (2009). Development as Localization: Ethnic Minorities in China's Official Discourse on the Western Development Project. Critical Asian Studies, 41(2), 225-254.

Barmé, G. R., \& Goldkorn, J. (Eds.) (2013). Civilising China: China Story Yearbook 2013. Canberra: ANU Press.

Bernstein, H. (2010). Rural Livelihoods and Agrarian Change: Bringing Class Back In. In N. Long, J. Ye, \& Y. Wang (Eds.), Rural Transformations and Development: China in Context: The Everyday Lives of Policies and People (pp. 79-109). Cheltenham: Edward Elgar Publishing.

Chambers, R. (1994). Participatory Rural Appraisal (PRA): Analysis of Experience. World Development, 22(9), 1253-1268.

Chambers, R. (2008). Revolutions in Development Inquiry. London: Earthscan. 
Chambers, R. (2014). Into the Unknown: Explorations in Development Practice. Rugby: Practical Action Publishing.

Chambers, R., \& Loubere, N. (2017). Liberating Development Inquiry: Freedom, Openness and Participation in Fieldwork. In G. Crawford, L. J. Kruckenberg, N. Loubere, \& R. Morgan (Eds.), Understanding Global Development Research: Fieldwork Issues, Experiences and Reflections (pp. 27-46). London and Thousand Oaks: SAGE.

Elyachar, J. (2005). Markets of Dispossession:NGOs, Economic Development, and the State in Cairo. Durham and London: Duke University Press.

Escobar, A. (1995). Encountering Development: The Making and Unmaking of the Third World. Princeton: Princeton University Press.

Escobar, A. (2004). Other Worlds are (Already) Possible: Self-organisation, Complexity, and Post-capitalist Cultures. World Social Forum: Challenging Empires, 349-358.

Foucault, M. (1982). The Subject and Power. Critical Inquiry, 8(4), 777-795.

Graeber, D. (2011). Debt: The First 5,ooo Years. New York: Melville House.

Guérin, I., \& Kumar, S. (2017). Market, Freedom and the Illusions of Microcredit. Patronage, Caste, Class and Patriarchy in Rural South India. The Journal of Development Studies, 53(5), 741-754.

Hathaway, T. (2016). Lukes Reloaded: An Actor-Centred Three-Dimensional Power Framework. Politics, $36(2)$, 118-130.

Hickel, J. (2015). The Microfinance Delusion: Who Really Wins? The Guardian. Retrieved 4 May 2019, from: http://www.theguardian.com/global-developmentprofessionals-network/2015/jun/10/the-microfinance-delusion-who-really-wins

Hirschman, A. O. (1967). Development Projects Observed. Washington D.C.: Brookings Institution Press.

Hobbes, M. (2014). Stop Trying to Save the World. The New Republic. Retrieved 4 May 2019, from: http://www.newrepublic.com/article/120178/ problem-international-development-and-plan-fix-it

Holland, J. (Ed.) (2013). Who Counts?: The Power of Participatory Statistics. Rugby: Practical Action Publishing.

Kahneman, D. (2012). Thinking, Fast and Slow. London: Penguin.

Kahneman, D., \& Tversky, A. (1979). Prospect Theory: An Analysis of Decision under Risk. Econometrica, 47(2), 263-291.

Karim, L. (2011). Microfinance and Its Discontents: Women in Debt in Bangladesh. Minneapolis: University of Minnesota Press.

Kirk, M., Brewer, J., \& Hickel, J. (2015). 4 Things You Probably Know About Poverty That Bill and Melinda Gates Don't. Retrieved 3 June 2015, from: http://www. fastcoexist.com/3041841/change-generation/4-things-you-probably-know-aboutpoverty-that-bill-and-melinda-gates-dont 
Li, T. M. (2007). The Will to Improve: Governmentality, Development, and the Practice of Politics. Durham and London: Duke University Press.

Lipsky, M. (1980). Street-Level Bureaucracy: Dilemmas of the Individual in Public Services. New York: Russell Sage Foundation.

Long, N. (1999). The Multiple Optic of Interface Analysis. UNESCO Background Paper on Interface (October), 1-28.

Long, N. (2001). Development Sociology: Actor Perspectives. London and New York: Routledge.

Loubere, N. (2017c). Questioning Transcription: The Case for the Systematic and Reflexive Interviewing and Reporting (SRIR) Method. Forum Qualitative Sozialforschung / Forum: Qualitative Social Research, 18(2).

Loubere, N. (2017d). Laying Off Responsibility: Microcredit, Entrepreneurship, and China's Industrial Retrenchment. In I. Franceschini, K. Lin, \& N. Loubere (Eds.), Made in China Yearbook 2016: Disturbances in Heaven (pp. 24-27). Canberra: ANU Press.

Lukes, S. (2005). Power: A Radical View (2nd ed.). New York: Palgrave Macmillan.

Mosse, D. (2010). A Relational Approach to Durable Poverty, Inequality and Power. Journal of Development Studies, 46(7), 1156-1178.

Murphy, R. (2004). Turning Peasants into Modern Chinese Citizens: "Population Quality” Discourse, Demographic Transition and Primary Education. The China Quarterly, 177, 1-20.

Ramalingam, B. (2013). Aid on the Edge ofChaos: Rethinking International Cooperation in a Complex World. Oxford: Oxford University Press.

Scott, J. (2012). Social Network Analysis. London and Thousand Oaks: SAGE.

Shah, A. (2017). Democracy of the Ground? Encountering Elite Domination during Fieldwork. In G. Crawford, L. Kruckenberg, N. Loubere, \& R. Morgan (Eds.), Understanding Global Development: Reflections on Fieldwork Experiences (pp. 4752). London and Thousand Oaks: SAGE.

Swansburg, J. (2014). The Self-Made Man: The Story of America's Most Pliable, Pernicious, Irrepressible Myth. Retrieved 17 July 2015, from: http://www.slate. com/articles/news_and_politics/history/2014/og/the_self_made_man_history_of_a_myth_from_ben_franklin_to_andrew_carnegie.html

Taylor, M. (2012). The Antinomies of 'Financial Inclusion': Debt, Distress and the Workings of Indian Microfinance. Journal of Agrarian Change, 12(4), 601-610.

Tilly, C. (1998). Durable Inequality. Berkeley and Los Angeles: University of California Press.

Tversky, A., \& Kahneman, D. (1992). Advances in Prospect Theory: Cumulative Representation of Uncertainty.Journal of Risk and Uncertainty, 5(4), 297-323. 
Weber, H. (2006). The Global Political Economy of Microfinance and Poverty Reduction: Locating Local “Livelihoods” in Political Analysis. In J. L. Fernando (Ed.), Microfinance: Perils and Prospects (pp. 37-54). London and New York: Routledge. World Bank (2014). Global Financial Development Report 2014: Financial Inclusion. Washington D.C.: The World Bank.

Yeh, E. T. (2013). Taming Tibet: Landscape Transformation and the Gift of Chinese Development. Ithaca and London: Cornell University Press.

Yunus, M., \& Weber, K. (2007). Creating a World Without Poverty: Social Business and the Future of Capitalism. New York: PublicAffairs. 
